\title{
Overweight and Obese Prevalence Rates in African American and Hispanic Children: An Analysis of Data from the 2003-2004 National Survey of Children's Health
}

\author{
May Nawal Lutfiyya, PhD, Rosemary Garcia, MD, Christine M. Dankwa, MPH, \\ Teriya Young, MD, and Martin S. Lipsky, MD, MS
}

Background: The prevalence of overweight and obesity was examined in African-American and Hispanic children compared with white children.

Methods: Multivariate analyses were performed on cross-sectional data from the National Survey of Children's Health collected in 2003 to 2004.

Results: Analyses found that overweight children were more likely to be African American and Hispanic than white, be male, live in households with incomes below $150 \%$ of the Federal poverty level, watch television 3 or more hours daily, and not have received preventive care in the past 12 months. Overweight children were less likely to get minimum levels of moderate physical activity or have participated on a sports team.

Conclusions: Poverty impacts childhood body mass index in at least 2 specific ways: unsafe neighborhoods and the cost and accessibility of healthy foods in low income communities. Addressing these issues require the concerted efforts of policy makers. The same is true for resolving the issues of children not receiving preventive care. Increasing the number of well child check-ups mandated by the government and required by school systems may be a beneficial policy. Furthermore, policymakers concerned with issues of childhood obesity may pursue the creation of school-based health clinics in schools where at least $50 \%$ of the student body live in households with incomes $<150 \%$ of the Federal poverty level. (J Am Board Fam Med 2008;21:191-199.)

Childhood overweight and obesity continues to be a growing concern both globally and in the United States. ${ }^{1,2}$ Within the last 30 years obesity rates have more than doubled in children aged 2 to 5 years and adolescents aged 12 to 19 years; rates among children ages 6 to 11 have tripled. ${ }^{1}$ In 2004 the Institute of Medicine estimated that more than 9 million children in the United States over the age of 6 were overweight. ${ }^{1}$

This article was externally peer reviewed.

Submitted 7 September 2007; revised 2 January 2008; accepted 22 January 2008.

From the Department of Family and Community Medicine, University of Illinois College of Medicine at Rockford (MNL, MSL); the Department of Internal Medicine, Residency Program, Kaiser Permanente, Santa Clara, CA (RG); and the Departmnet of Family and Community Medicine, Residency Program, Baylor University, Houston, TX (TY).

Funding: none.

Conflict of interest: none declared.

Corresponding author: M. Nawal Lutfiyya, PhD, Department of Family and Community Medicine, University of Illinois-Chicago College of Medicine at Rockford, Rockford, Illinois 61107 (E-mail: lutfiyya@uic.edu).
Studies have shown that children who are overweight are more likely to become overweight or obese adults. ${ }^{1,3,4}$ This is a concern because adult overweight and obesity are risk factors for health conditions such as hypertension and type 2 diabetes, which negatively impact morbidity and mortality. ${ }^{5-8}$ In addition to increasing the risk for future disease, being overweight or obese during childhood has important short-term metabolic effects; it adversely affects growth, blood pressure, lipids, and glucose and places a child at increased risk for other health-related complications such as respiratory and musculoskeletal conditions. Perhaps equally important to the physical problems are the negative psychosocial consequences. Obese children have an increased sense of loneliness, sadness, and nervousness and are more likely to engage in risk-taking behaviors such as tobacco use and alcohol consumption. ${ }^{9}$

Although the rate of overweight is increasing for all children in the United States, there is some evidence to suggest that African-American and 
Hispanic children are at greater risk for being overweight or obese. ${ }^{1,10-13}$ According to the Institute of Medicine, up to $24 \%$ of African-American and Hispanic children are above the 95th percentile for body mass index (BMI) measurement. ${ }^{1}$ Furthermore, the highest prevalence of childhood obesity among boys has been observed in Hispanics, whereas the highest prevalence among girls was found in African-Americans. ${ }^{1}$

Despite extensive research documenting race and ethnicity as a risk factor for childhood obesity, no single data source provides information on the trends for all the major racial and ethnic groups. Various limitations, such as the use of geographically limited databases ${ }^{4,14-16}$ or the failure to include the entire range of school-aged children, still leave gaps in our knowledge. ${ }^{4,14-17}$ Some studies also treat race as a single category; by not examining for differences in risk among an ethnic group, opportunities for effectively developing targeted interventions may be missed.

A number of studies have forwarded reasons for childhood overweight and obesity. ${ }^{18,19}$ These include nutrition practices, ${ }^{20-22}$ child activity levels, ${ }^{23,24}$ genetic $^{19,25,26}$ and metabolic factors, ${ }^{27,28}$ socioeconomic disadvantage,${ }^{29,30}$ child temperament, ${ }^{31,32}$ and family neglect. ${ }^{33}$ Pulling from the findings of these earlier research efforts we examined the prevalence of overweight and obesity in African-American and Hispanic children compared with white children using the National Survey of Children's Health (NSCH). This study sought to determine what factors, if any, included in the NSCH survey might be associated with overweight and obesity in African-American and Hispanic school-aged (5 to 18 years old) children. Specifically, analyses explored whether or not obesity prevalence varied by demographic characteristics and several other covariates, such as parents' physical activity levels, health service use regarding preventive care, number of hours spent watching television, hours of nonschool computer use, and the child's amount of physical activity. Because some other studies tend to consider African-Americans or Hispanics as a single entity, identifying the presence of unique factors contributing to overweight and obesity would likely be useful for developing targeted prevention and intervention strategies.

\section{Methods}

This study is an analysis of secondary data from the NSCH, collected in 2003 and 2004. School-aged children (ages 5 to 18 years) were the population of interest. NSCH is a random digit dial survey conducted by the Centers for Disease Control and Prevention's National Center for Health Statistics and is a part of the State and Local Area Integrated Telephone Survey program. For data collection, one child from each identified household was randomly selected and data were generated through a phone interview with the parent or guardian in the household who was the most familiar with the targeted child. The NSCH collects data in 8 domains, including demographics, physical and mental health status, health insurance, health care use and access to health care, medical home, family functioning, parents' health, and neighborhood characteristics. A full description of the NSCH and the development of sampling frames have been extensively described in other publications. ${ }^{34}$ Consent for participation in the study was obtained from interview respondents as soon as it was determined that their household contained a child of eligible age. At that time, respondents were informed about the voluntary nature of the survey, the authorizing legislation, and confidentiality of data collected. ${ }^{34}$

For our study data for the year 2003 to 2004 were analyzed (unweighted, $\mathrm{n}=62,976 ; 21,715$ of this sample were overweight or obese). All analyses were performed on weighted data (only weighted numbers appear in the tables). The data were weighted to be representative of the child population in the United States while maintaining complete subject anonymity. The weighting variable is calculated by the Centers for Disease Control and Prevention using the most recently available census data to provide a stratified representation of the nation's children.

A number of the variables were recoded for our analysis. Recoding consisted of collapsing response categories to gain a more meaningful analysis. The variables, original survey questions used for data generation and the recoded categories used in the analyses, are displayed in Table 1.

Sex- and age-specific BMI percentiles were used to measure overweight or obesity among children. For this measure the BMI number was calculated the same way for children as adults $(\mathrm{BMI}=[$ weight in lbs / height in inches $\left.\left.{ }^{2}\right] \times 703\right)$; however, the 
Table 1. Variables, Original Survey Questions, and Recoded Factors Used in Analysis of 2003-2004 Data from National Survey of Children's Health

\begin{tabular}{|c|c|c|}
\hline Variable & National Survey of Children's Health Question & Recoded for Descriptive Analysis \\
\hline $\begin{array}{l}\text { Household income as } \\
\text { percent of FPL }\end{array}$ & $\begin{array}{l}\text { Two variables were used to determine a household's } \\
\text { poverty status: the number of people residing in a } \\
\text { household and the household's income during the } \\
\text { prior year. }\end{array}$ & $\begin{array}{l}\leq 150 \% \mathrm{FPL} \\
>150 \% \mathrm{FPL}\end{array}$ \\
\hline $\begin{array}{l}\text { Child's nonschool } \\
\text { computer use }\end{array}$ & $\begin{array}{l}\text { On an average school day, about how many hours does } \\
\text { [the child] use a computer for purposes other than } \\
\text { schoolwork? }\end{array}$ & $\begin{array}{l}<1 \mathrm{hr} \\
\text { between } 1 \text { and } 2 \mathrm{hr} \\
\geq 3 \text { hours }\end{array}$ \\
\hline Child's television use & $\begin{array}{l}\text { On an average school day, about how many hours does } \\
\text { [the child] usually watch television, watch videos, or } \\
\text { play video games? }\end{array}$ & $\begin{array}{l}<1 \mathrm{hr} \\
\text { between } 1 \text { and } 2 \mathrm{hr} \\
\geq 3 \text { hours }\end{array}$ \\
\hline Child's physical activity & $\begin{array}{l}\text { During the past week, on how many days did [the } \\
\text { child] exercise or participate in physical activity for } \\
\text { at least } 20 \text { minutes that made [him/her] sweat and } \\
\text { breathe hard, such as basketball, soccer, running, } \\
\text { swimming laps, fast bicycling, fast dancing, or } \\
\text { similar aerobic activities? }\end{array}$ & $\begin{array}{l}\text { Yes ( } \geq 5 \text { days coded as Yes for getting } \\
\text { minimum amounts of moderate } \\
\text { physical activity) } \\
\text { No ( }<5 \text { days coded as No for not } \\
\text { getting minimum amounts of } \\
\text { moderate physical activity) }\end{array}$ \\
\hline Sports team participant & $\begin{array}{l}\text { During the past } 12 \text { months, was [the child] on a sports } \\
\text { team or did [he/she] take sports lessons after school } \\
\text { or on weekends? }\end{array}$ & $\begin{array}{l}\text { Yes } \\
\text { No }\end{array}$ \\
\hline Have health plan & $\begin{array}{l}\text { Does [the child] have any kind of health care coverage, } \\
\text { including health insurance, prepaid plans such as } \\
\text { HMOs, or government plans such as Medicaid? }\end{array}$ & $\begin{array}{l}\text { Yes } \\
\text { No }\end{array}$ \\
\hline $\begin{array}{l}\text { Received all preventive care } \\
\text { during the past } 12 \text { mo }\end{array}$ & $\begin{array}{l}\text { During the past } 12 \text { months/Since [the child's] birth, } \\
\text { did [he/she] visit [his/her] personal doctor or nurse } \\
\text { for preventive care? } \\
\text { (Preventive care visits include things like a well-child } \\
\text { check-up, a routine physical exam, immunizations, } \\
\text { or health screening tests.) }\end{array}$ & $\begin{array}{l}\text { Yes } \\
\text { No }\end{array}$ \\
\hline Have PCP & $\begin{array}{l}\text { Do you have one or more people you think of as [the } \\
\text { child's] personal doctor or nurse? }\end{array}$ & $\begin{array}{l}\text { Yes } \\
\text { No }\end{array}$ \\
\hline Race & $\begin{array}{l}\text { Is [the child] white, African-American, American } \\
\text { Indian, Alaskan native, Asian, or native Hawaiian or } \\
\text { other Pacific Islander? }\end{array}$ & $\begin{array}{l}\text { white } \\
\text { Not white }\end{array}$ \\
\hline Sex & Is [the child] male or female? & $\begin{array}{l}\text { Male } \\
\text { Female }\end{array}$ \\
\hline $\begin{array}{l}\text { Father/mother meeting at } \\
\text { least recommended levels } \\
\text { of moderate physical } \\
\text { activity? }\end{array}$ & $\begin{array}{l}\text { During the past week, on how many days did you } \\
\text { exercise or participate in physical activity for at least } \\
20 \text { minutes that made you sweat and breathe hard, } \\
\text { such as basketball, soccer, running, swimming laps, } \\
\text { fast bicycling, fast dancing, or similar aerobic } \\
\text { activities? }\end{array}$ & $\begin{array}{l}\text { Yes ( } \geq 5 \text { days coded as Yes for getting } \\
\text { minimum amounts of moderate } \\
\text { physical activity) } \\
\text { No ( }<5 \text { days coded as No for not } \\
\text { getting minimum amounts of } \\
\text { moderate physical activity) }\end{array}$ \\
\hline
\end{tabular}

FPL, Federal poverty level; HMO, health maintenance organization.

criteria used to interpret the meaning of the BMI number for children is different. Once the BMI is calculated, its percentile must be determined using a sex- and age-specific BMI percentile chart. Results are interpreted as follows: underweight, $<5$ th percentile; normal weight, [mteq] 5 th percentile, $<85$ th percentile; overweight, [mteq] 85 th, $<95$ th percentile; obese, [mteq]95th percentile. Underweight children were not included in this analysis but the proportion of children in our population sample who were underweight is reported in Table 2.

SPSS software version 15.0 (SPSS, Chicago, IL) was used to complete all statistical analyses per- formed for this study. Univariate descriptions of and bivariate comparisons were made using an unadjusted odds ratio (OR) to test for differences between and within groups. Multivariate logistic regression was performed to ascertain adjusted ORs. Logistic regression refers to statistical models where the dependent, or outcome variable, is categorical. In this study the logistic regression model was performed to predict characteristics of overweight and obese school-aged children compared with healthy weight school-aged children (or with not being overweight or obese). For all analyses, $\alpha$ was set at $<0.05$. This study was approved by the 
Table 2. Body Mass Index Classification for Age and Gender by Race and Ethnicity (from 2003 to 2004 National Survey of Children's Health Data)

\begin{tabular}{lcc}
\hline & & Race and Ethnicity $(\%)$ \\
\cline { 2 - 3 } Child's BMI Classification & $\begin{array}{c}\text { Caucasian } \\
(\mathrm{n}=30,713,665)^{*}\end{array}$ & $\begin{array}{c}\text { African American } \\
(\mathrm{n}=7,109,284)^{*}\end{array}$ \\
\hline Underweight & 6.8 & 6.1 \\
Healthy weight & 61.0 & 6.4 \\
Overweight and obese & 32.2 & 44.7 \\
\hline
\end{tabular}

${ }^{*}$ Weighted samples (unweighted n's: Caucasian = 49,854, African American = 6,696, Hispanic = 6,426)

University of Illinois Chicago College of Medicine at Rockford's Institutional Review Board.

\section{Results}

Using BMI, Table 2 displays the proportion of children by race and ethnicity who are underweight and who reported having a healthy weight compared with those who are overweight or obese. Although $32.2 \%$ of white children were overweight or obese, $49.2 \%$ of the African-American children and $44.0 \%$ Hispanic children were overweight or obese. Table 3 presents the findings from the bivariate analysis by race and ethnicity. A higher proportion of Hispanic children were overweight for most of the categories of the predictor or independent variables compared with African-American and white children. For example, a larger proportion $(36.9 \%)$ of overweight or obese Hispanic children did not get recommended levels of physical activity when compared with overweight or obese white children. Additionally $70.0 \%$ of obese or overweight Hispanic children lived in households with annual incomes $<150 \%$ of the Federal poverty level compared with overweight or obese white children. This pattern continued for the level of parental physical activity, with higher proportions of both the mothers and fathers of overweight or obese Hispanic school-aged children not engaging in recommended levels of moderate physical activity. When assessing hours of television viewing and nonschool computer use, a larger proportion (36.4\%) of overweight African-American children reported 3 or more hours of daily television viewing when compared with overweight Hispanic and white children (25.1\% and $19.9 \%$, respectively). Higher proportions of overweight African-American children also reported nonschool computer use 3 or more hours daily $(11.8 \%$ vs $8.4 \%$ for white and 9.9\% for Hispanic overweight school-aged children).

Four logistic regression models were tested and the results are displayed in Table 4.

For the first model tested, the dependent variable was all overweight or obese children; the sec-

Table 3. Description of Overweight and/or Obese School-Aged Children by Race/Ethnicity and the Study's Independent Variables (from 2003 to 2004 National Survey of Children's Health Data)

\begin{tabular}{lccc}
\hline Covariates & $\begin{array}{c}\text { Caucasian } \\
(\mathrm{n}=9,889,800)\end{array}$ & $\begin{array}{c}\text { African American } \\
(\mathrm{n}=3,497,768)\end{array}$ & $\begin{array}{c}\text { Hispanic } \\
(\mathrm{n}=2,454,708)\end{array}$ \\
\hline Child's household income $<150 \%$ FPL & 31.6 & 62.2 & 70.0 \\
Child did not receive preventive care during the past 12 mo & 30.7 & 23.1 & 30.4 \\
Child not meeting at least recommended levels of moderate PA & 32.4 & 32.4 & 36.9 \\
Father not meeting at least recommended levels of moderate PA & 31.0 & 29.7 & 39.3 \\
Mother not meeting at least recommended levels of moderate PA & 40.6 & 45.5 & 49.2 \\
Child not a sports team participant & 53.5 & 43.4 & 43.8 \\
Child viewing $\geq 3$ hr of daily television & 19.9 & 36.4 & 11.8 \\
Child nonschool computer use $\geq 3$ hours daily & 8.4 & 9.9 \\
\hline
\end{tabular}

All data presented as percents. This represents a weighted analysis. Underweighted children by BMI measure were not included in the analysis.

FPL, Federal poverty level; PA, physical activity. 
Table 4. Multivariate Logistic Regression Results Characteristics of Overweight and/or Obese School-Aged Children Compared with Healthy Weight Children* (from 2003 to 2004 National Survey of Children's Health Data)

\begin{tabular}{|c|c|c|c|c|}
\hline Independent Variables and Factors & $\begin{array}{l}\text { All US } \\
\text { Children }\end{array}$ & $\begin{array}{c}\text { African-American } \\
\text { Children }\end{array}$ & $\begin{array}{l}\text { Hispanic } \\
\text { Children }\end{array}$ & $\begin{array}{l}\text { White } \\
\text { Children }\end{array}$ \\
\hline \multicolumn{5}{|l|}{ Race and ethnicity (white) } \\
\hline African-American & $1.568(1.562-1.574)$ & & & \\
\hline Hispanic & $1.298(1.293-1.303)$ & & & \\
\hline \multicolumn{5}{|l|}{ Sex (female) } \\
\hline Male & $1.579(1.575-1.583)$ & $1.279(1.269-1.288)$ & $1.603(1.591-1.615)$ & $1.635(1.630-1.640)$ \\
\hline \multicolumn{5}{|l|}{ Household income (>150\% FPL) } \\
\hline$\leq 150 \% \mathrm{FPL}$ & $1.540(1.535-1.545)$ & $1.219(1.210-1.229)$ & $2.002(1.987-2.016)$ & $1.537(1.531-1.543)$ \\
\hline \multicolumn{5}{|l|}{ Preventive care during past 12 mo (Yes) } \\
\hline No & $1.540(1.535-1.545)$ & $1.219(1.210-1.229)$ & $2.002(1.987-2.016)$ & $1.537(1.531-1.543)$ \\
\hline \multicolumn{5}{|l|}{ Father meeting at least recommended levels of moderate PA } \\
\hline Not meeting recommended levels of moderate PA & $0.902(0.899-0.904)$ & $0.881(0.873-0.888)$ & $0.662(0.657-0.668)$ & $0.948(0.945-0.951)$ \\
\hline \multicolumn{5}{|c|}{ Mother meeting at least recommended levels of moderate PA } \\
\hline Not meeting recommended levels of moderate PA & $1.146(1.143-1.149)$ & $0.995(0.987-1.003)$ & $1.133(1.124-1.142)$ & $1.182(1.178-1.186)$ \\
\hline \multicolumn{5}{|l|}{ Child meeting at least recommended levels of moderate PA } \\
\hline Not meeting recommended levels of moderate PA & $1.416(1.412-1.420)$ & $1.605(1.592-1.618)$ & $1.251(1.241-1.261)$ & $1.413(1.409-1.418)$ \\
\hline \multicolumn{5}{|l|}{ Sports Team Participant (Yes) } \\
\hline No & $1.343(1.339-1.347)$ & $1.266(1.256-1.275)$ & $1.508(1.496-1.519)$ & $1.341(1.336-1.345)$ \\
\hline \multicolumn{5}{|l|}{ Child's nonschool computer use ( $<1 \mathrm{hr})$} \\
\hline Between 1 and $2 \mathrm{hr}$ & $0.942(0.940-0.945)$ & $1.065(1.057-1.073)$ & $0.873(0.866-0.880)$ & $0.925(0.922-0.928)$ \\
\hline$\geq 3 \mathrm{hr}$ & $1.091(1.086-1.096)$ & $0.977(0.966-0.989)$ & $1.523(1.502-1.543)$ & $1.081(1.075-1.088)$ \\
\hline \multicolumn{5}{|l|}{ Child's television use ( $<1 \mathrm{hr}$ ) } \\
\hline Between 1 and $2 \mathrm{hr}$ & $1.312(1.308-1.316)$ & $1.249(1.237-1.261)$ & $0.985(0.975-0.994)$ & $1.370(1.365-1.375)$ \\
\hline$\geq 3 \mathrm{hr}$ & $1.685(1.678-1.692)$ & $1.565(1.548-1.582)$ & $1.272(1.257-1.287)$ & $1.814(1.805-1.823)$ \\
\hline
\end{tabular}

All values presented as odds ratio $(95 \% \mathrm{CI})$. This represents a weighted analysis. Underweighted children by BMI measure were not included in the analysis, nor were children of races/ethnicities other than Caucasian, African American, or Hispanic.

ond logistic regression model included only overweight or obese African-American children as the dependent variable whereas the dependent variable for the third model tested was overweight or obese Hispanic children. The fourth and last logistic regression model included overweight or obese white children as the dependent variable. The results of the first multivariate model yielded that overweight or obese children aged $\geq 5$ years were more likely to be African-American (OR 1.568; 95\% CI, 1.562-1.574) and Hispanic (OR 1.298; 95\% CI, 1.293-1.303) than white. Male children rather than female children were more likely to be overweight or obese in all 4 tested models. Overweight or obese children from all 4 models tested were more likely to live in households with incomes below $150 \%$ of Federal poverty level compared with households with incomes $>150 \%$ of the Federal poverty level and to have not received preventive care in the past 12 months. With respect to physical activity, all of the models tested found that overweight and obese children were less likely to get the minimum levels of moderate physical activity and were less likely to have participated on a sports team. Overall, overweight or obese children were also more likely to have a mother who did not get at least recommended levels of moderate activity. This was also true for school-aged overweight or obese Hispanic and white children; however, the results for mothers of African-American children were inconclusive. All overweight or obese children across the 4 models tested were less likely to have a father who met recommended levels of moderate physical activity. In all logistic regression models tested, overweight or obese children were more likely to watch $\geq 3$ hours of television daily than they were to watch $<1$ hour of television. Finally, with regard to nonschool computer use, overweight or obese Hispanic and white children were more likely to use the computer for $\leq 3$ hours daily than they were to use it for $<1$ hour.

\section{Discussion}

Similar to other recently published studies, ${ }^{1,2,11}$ our findings indicate that, when compared with white 
school-aged children, African-American and Hispanic children were more likely to be overweight and/or obese. For African-American children the increased risk was slightly more than $50 \%$ compared with white children, whereas it was approximately $30 \%$ for Hispanic children. Our finding that children of poorer families are more likely to be overweight or obese is also consistent with previous studies that demonstrated that children in lower income groups are at higher risk of being overweight or obese. ${ }^{2,35-37}$ Because African-American and Hispanic families are 3 times more likely than whites to live in poverty, ${ }^{2,38}$ socioeconomic status clearly places these groups at risk.

Unraveling the relative impact of socioeconomic status, race, and ethnicity to health disparities is difficult. Income impacts childhood BMI in at least 2 specific ways that cross racial and ethnic boundaries: (1) unsafe neighborhoods and (2) the cost and accessibility of healthy foods in low-income communities. Children living in low income neighborhoods are more likely to face safety concerns, which may make physical activity through outside play less likely, and more likely to have poorer access to stores that carry healthier food choices such as fresh fruits and vegetables and whole grain and low-fat dairy products. ${ }^{39}$ Even if available, such foods are often less obtainable to families with limited financial means.

However, our results did differ from earlier research $^{38}$ by finding that the association of living in a poorer household and being overweight or obese was strongest for Hispanic children than for white or African-Americans. The reason why these children may be more vulnerable to living in poverty is unclear and could be related factors such as language or an enhanced susceptibility to the marketing of calorie-dense fast food. ${ }^{40}$ Further study to corroborate this finding and to explore possible explanations would likely be helpful for developing strategies to address obesity in Hispanic children.

Among school aged children of the 3 races/ ethnicities examined here, boys were more likely to be overweight or obese than girls. Another finding was that overweight or obese school-aged children of all 3 racial/ethnic groups had a slightly greater likelihood of not receiving preventive care in the past 12 months. Although the association between childhood overweight and obesity and receiving preventive care makes intuitive sense, this study is the first to provide evidence of this relationship.
Hispanic children who did not have a preventive health visit were $22 \%$ more likely to be overweight or obese, a much higher chance compared with African-American or white children and a finding that may be helpful for developing interventions targeted at Hispanic children. For example increasing the number of well child check-ups that are mandated by government agencies and/or required by school systems and during which family physicians, pediatricians, or nurse practitioners could provide counseling and education about nutrition and exercise might be a policy of benefit. Furthermore, policymakers concerned with issues of childhood obesity might pursue the creation of schoolbased health clinics in schools where at least $50 \%$ of the student body live in households with incomes $<150 \%$ of the Federal poverty level. These clinics could be located in schools, contract for physician and nurse practitioner time, and provide medical services for both students and their families. In addition, if children are not visiting physician offices for preventive care, alternative points of intervention such as Parent Teacher Association meetings or other school-initiated events should be considered. These events could also be viewed as opportunities to address healthy nutrition in the context of family because unhealthy parental lifestyles increase the risk of childhood obesity. Interventions in which both parents and children interactively learn about nutrition and strategies for a healthy diet could be used to teach parents how to shop for healthy food within the context of limited resources and potentially restricted shopping options.

Not surprisingly, physical activity levels and participation on sports teams emerged as significant factors related to childhood overweight and obesity for all $3 \mathrm{racial} /$ ethnic groups of school-aged children. Although all groups of overweight or obese children were more likely to not get recommended amounts of at least moderate physical activity, the likelihood was greater for overweight and obese African-American school-aged children. One possible factor contributing to lower levels of exercise is that both overweight and obese African-American and Hispanic school-aged children were less likely to participate on sports teams, particularly Hispanic school-aged children, who had higher odds of not participating than the African-American children. Sports team participation may very well be connected to a family's financial circum- 
stances; fees for participation and uniforms or other equipment might very well exclude a child from participating. That Hispanic children were less likely to participate in organized sports suggests that cultural differences might also play an important role.

Previous work by Dennison et al found that the mean television/video viewing time was higher for African-American and Hispanic children than White children and concluded that this increased the risk for overweight in those populations. ${ }^{41}$ Our findings partially support Dennison et al's findings. Overweight or obese Hispanic children were also more likely than their healthy weighted counterparts to engage in $\geq 3$ hours of nonschool computer use daily; overweight or obese African-American children were more likely to watch $\geq 3$ hours of television daily. Ultimately, spending time in these passive activities may decrease a child's time spent engaged in physical activity of some form. Future studies should examine what these types of activities (watching television and computer use) mean for these different groups of children to devise interventions that might redirect their attention to physical activity or incorporate television viewing and/or computer use into physically active avenues.

There are several limitations to this study. First, our attempt to parse out the effect of race/ethnicity from socioeconomic status was limited by the data collected. Perhaps with more parameters to more specifically define socioeconomic status, ethnicity/ race effect might be attenuated. Second, the data are self-reported and subject to error. However, the bias would most likely be to under-report overweight and/or obesity, suggesting that the prevalence of such might be even higher. Third, although several confounding variables associated with obesity were accounted for, it is possible other unidentified factors may account for the increased risk of obesity. For instance, the survey did not ask parents to describe the neighborhood or environments they lived in nor was parental BMI, one of the strongest predictors of childhood obesity, assessed. ${ }^{19,39,42}$ Future research to further unravel factors contributing to obesity in the AfricanAmerican and Hispanic child population may aid in developing effective strategies geared to preventing obesity. The NCHS survey did not query parents about either their children's eating habits or more broad family nutrition patterns. To fully understand issues related to overweight and obesity, eat- ing habits and nutritional patterns are important considerations. ${ }^{43,44}$ In addition, although participation on a sports team emerged as a significant factor related to childhood overweight and obesity, there is no way of knowing from the collected data what barriers, if any, African-American and Hispanic children may have encountered that prevented such participation. For example, some of the children included in the study may have attended schools that did not have sports teams or some of the children in the study may not have been able to participate on sports teams because they needed transportation that was not available to them or they may not have been able to pay necessary fees (eg, for uniforms or other equipment). Future efforts should consider collecting data about these issues. Finally, although excessive time watching television was predictive of childhood risk for being overweight or obese, data were not collected about whether or not the child had a television in his/her bedroom. Again such data could prove informative to the development of public health interventions. Conclusion

The prevalence of overweight and obese children is higher among African-American and Hispanic populations than among their white peers. Effectively addressing this disparity will require a greater understanding of its causes and what factors might magnify the risk among minority populations. Despite the identified limitations, the research findings presented here offer some important insights into the issues surrounding overweight and obesity in African-American and Hispanic children in the United States. Further study is still needed to more completely understand how the various aspects of social, cultural, and economic factors place these children at risk and to develop effective strategies for combating the epidemic of childhood obesity.

\section{References}

1. Institute of Medicine. Childhood obesity in the United States: facts and figures. 2004. Available at http://www.iom.edu/Object.File/Master/22/606/ FINALfactsandfigures2.pdf. Accessed 8 February 2008.

2. Crawford PB, Story M, Wang MC, Ritchie LD, Sabry ZI. Ethnic issues in the epidemiology of childhoodo. Pediatr Clin North Am 2001;48:855-78.

3. Freedman DS, Khan LK, Serdula MK, Dietz WH, Srinivasan SR, Berenson GS. Racial differences in 
the tracking of childhood BMI to adulthood. Obes Res 2005;13:928-35.

4. Popkin BM, Udry JR. Adolescent obesity increases significantly in second and third generation US immigrants: The National Longitudinal Study of Adolescent Health. J Nutr 1998;128:701-6.

5. US Department of Health and Human Services, US Department of Agriculture. Dietary guidelines for Americans, 2005. 6th ed. Washington, DC: US GPO; 2005.

6. Must A, Strauss RS. Risk and consequences of childhood and adolescent obesity. Int J Obes 1999;23:S2S11.

7. Deckelbaum R, Williams CL. Childhood obesity: the health issue. Obes Res 2001;9:239S-43S.

8. Sorof JM, Lai D, J Turner, Poffenbarger T, Portmanverweight RJ. Ethnicity and the prevalence of hypertension in school-aged children. Pediatrics 2004;113:475-82.

9. Strauss RS. Childhood obesity and self-esteem. Pediatrics 2000;105:1-5.

10. Larsen L, Mandleco B, Williams M, Tiedeman M. Childhood obesity: prevention practices of nurse practitioners. J Am Acad Nurse Pract 2006;18:70-9.

11. Centers for Disease Control and Prevention, National Center for Health Statistics. Prevalence of overweight among children and adolescents: United States, 1999-2000. 2003. Available at http://www. cdc.gov/nchs/products/pubs/pubd/hestats/overwght99. htm. Accessed 8 February 2008.

12. Rocchini AP. Childhood obesity and a diabetes epidemic. N Engl J Med 2002;346:854-5.

13. Strauss RS. Childhood obesity. Pediatr Clin North Am 2002;49:175-201.

14. Mirza NM, Kadow K, Palmer M, Solano H, Rosche C, Yanovski JA. Prevalence of overweight among inner city Hispanic-American children and adolescents. Obes Res 2004;12:1298-310.

15. Rio-Navarro BE, Velaz ques-Monroy O, SanchezCostillo CP, et al. The high prevalence of overweight and obesity in Mexican children. Obes Res 2004;12:215-33.

16. Vandwater EA, Skem M, Caplovitz AG. Linking obesity and activity level with children's television and video game use. J Adolesc 2004;27:71-85.

17. Strauss RS, Pollack HA. Epidemic increase in childhood overweight, 1986-1998. JAMA 2001;286:2845-8.

18. O'Callaghan MJ, Williams GM, Andersen MJ, Bor W, Najman JM. Prediction of obesity in children at 5 years: a cohort study. J Paediatr Child Health. 1997;33:311-6.

19. Ebbeling CB, Pawlak DB, Ludwig DS. Childhood obesity: public-health crisis, common sense cure. Lancet 2002;360:473-82.

20. Swinburn BA, Caterson I, Seidell JC, James WPT. Diet, nutrition and the prevention of excess weight gain and obesity. Public Health Nutr 2004;7:12346.

21. Zive MM, McKay H, Frank-Spohrer GC, Boyles SL, Nelson JA, Nader PR. Infant feeding practices and adiposity in 4-year-old Anglo and Mexican Americans. Am J Clin Nutr 1992;556:1104-8.

22. Armstrong J, Dorosty AR, Reilly JJ, Emmett PM, Child Health Information Team. Coexistence of social inequalities in undernutrition and obesity in preschool children: population based cross sectional study. Arch Dis Child 2003;88:671-5.

23. Moore LL, Di Gao AS, Loring Bradlee ML, et al. Does early physical activity predict body fat change throughout childhood? Prev Med 2003;37:10-7.

24. Ruowei L, O'Connor 'T, Buckley D, Specker B. Relation of activity levels to body fat in infants 6-12 months of age. J Pediatr 1995;126:353-7.

25. Herbert A, Gerry NP, McQueen MB, et al. A common genetic variant is associated with adult and childhood obesity. Science 2006;312:279-83.

26. Lindpaintner K. Finding an obesity gene a tale of mice and man. N Engl J Med 1995;332:679-80.

27. Metzger BE, Buchanan TA, Coustan DR, et al. Summary and recommendations of the fifth international workshop-conference on gestational diabetes mellitus. Diabetes Care 2007;30:S251-S260.

28. Leibel R, Rosenbaum M, Hirsch J. Changes in energy expenditure resulting from altered body weight. N Engl J Med 1995;332:621-8.

29. Galobardes B, Smith G, Lynch J. Systematic review of the influence of childhood socioeconomic circumstances on risk for cardiovascular disease in adulthood. Ann Epidemiol 2006;16:91-104.

30. Stunkard AJ, Sorensen TIA. Obesity and socioeconomic status: a complex relation. $\mathrm{N}$ Engl J Med 1993;329:1036-7.

31. Carey WB. Temperament and increased weight gain in infants. J Dev Behav. Pediatr 1985;6:128-31.

32. Agras WS, Hammer LD, Mcnicholas F, Kraemer HC. Risk factors for childhood overweight: a prospective study from birth to 9.5 years. J Pediatr 2004;145:20-5.

33. Christoffel KK, Forsyth BWC. Mirror image of environmental deprivation; severe childhood obesity of psychosocial origin. Child Abuse Negl 1989;13:249_56.

34. Blumberg SJ, Olson L, Frankel MR, Osborn L, Srinath KP, Giambo P. Design and operation of the National Survey of Children's Health, 2003. Vital Health Stat 1 (43). Hyattsville (MD): National Center for Health Statistics; 2005.

35. Jain A, Sherman S, Chamberalin L. Why don't lowincome mothers worry about their preschoolers being overweight. Pediatrics 2001;107:1138-46.

36. McArthur LH, Anguiano R, Gross KH. Are household factors putting immigrant Hispanic children at risk of becoming overweight: a community-based 
study in eastern North Carolina. J Community Health 2004;29:387-404.

37. Gordon-Larsen P, Adair L, Popkin B. The relationship of ethnicity, socioeconomic factors, and overweight in US adolescents. Obes Res 2003;11:597.

38. Wang Y. Cross-national comparison of childhood obesity: the epidemic and the relationship between obesity and socioeconomic status. Int J Epidemiol 2001;30:1129-36.

39. Krebs NF, Jacobson MS, American Academy of Pediatrics Committee on Nutrition. Prevention of pediatric overweight and obesity. Pediatrics 2003;112: 424-30.

40. Alaimo K, Olson CM, Frongillo EA. Low family income and food insufficiency in relation to overweight in US children: is there a paradox? Arch Pediatr Adolesc Med 2001;155:1161-7.
41. Dennison BA, Erb TA, Jenkins PL. Television viewing and television in bedroom associated with overweight risk among low-income preschool children. Pediatrics 2002;109:1028-35.

42. Danielzik S, Langnase K, Mast M, Spethmann C, Muller MJ. Impact of parental BMI on the manifestation of overweight 5-7 year old children. Eur J Nutr 2002;41:132-8.

43. Berkey CS, Rockett HRH, Field AE, et al. Activity, dietary intake, and weight changes in a longitudinal study of preadolescent and adolescent boys and girls. Pediatrics 2000;105:e56.

44. Crespo CJ, Smit E, Troiana RP, Bartlett SJ, Macera $\mathrm{CA}$, Andersen RE. Television watching, energy intake, and obesity in US children. Arch Pediatr Adolesc Med 2001;155:360-5. 